\title{
Commentary: My best was never good enough, Bruce Springsteen
}

\author{
David B. Meyer, MD
}

From Cohen Children's Medical Center, Northwell Health System, Zucker-Hofstra School of Medicine, Hempstead, NY.

Disclosures: Author has nothing to disclose with regard to commercial support.

Received for publication Dec 7, 2018; accepted for publication Dec 7, 2018.

Address for reprints: David B. Meyer, MD, 260-01 76th Ave, New Hyde Park, NY 11040 (E-mail: dmeyer@ northwell.edu).

J Thorac Cardiovasc Surg 2019;157:1590

$0022-5223 / \$ 36.00$

Copyright $(c) 2018$ by The American Association for Thoracic Surgery

https://doi.org/10.1016/j.jtcvs.2018.12.024

Jegatheeswaran and colleagues ${ }^{1}$ have provided an update on outcomes for patients in the Congenital Heart Surgeons' Society registry for interrupted aortic arch (IAA) surgery repairs done from 1987 to 1997. I applaud the focus on functional health status rather than durability of aortic repair or other surgical outcomes. Specifically, surgical outcomes have been reported, ${ }^{2,3}$ but less is available on overall health status. In an era of increasing surgical outcome transparency, it is equally important that we provide parents with a realistic sense of how life will likely be for a fetus with diagnosed with congenital heart disease. Having recently joined other Congenital Heart Surgeons' Society registry working groups, I have a deeper understanding of effort and resource needed to maintain and query the registry. It is a huge task, and these registries represent some of the best data available for study.

Surgeons will be pleased to note the generally favorable responses that were returned by these patients on the functional health surveys. In several domains (mental health and freedom from bodily pain in older patients, and even additional domains for younger patients) the scores were actually greater than normative comparison data. In only one domain for the older aged group (physical functioning) were the scores lower than normative controls. It is heartening that a substantial proportion of patients with IAA are able years later to live life free from substantial health limitation.

The generalizability of these positive responses to the overall IAA patient cohort, however, may be limited by the construct of the registry and method of measurement. Submission of patients to the registry was voluntary, and not all patients with the diagnosis needed to be submitted, leading to potential selection bias. This study includes less than $50 \%$ of the original cohort. Almost $20 \%$ of returned questionnaires were excluded because they were completed by a caregiver, perhaps due to patients' cognitive impairment-mean functional health scores might indeed have brought down the average if included. Another sizeable portion of the original cohort has died. Thus, the responders in the study probably represent the better of the outcomes.

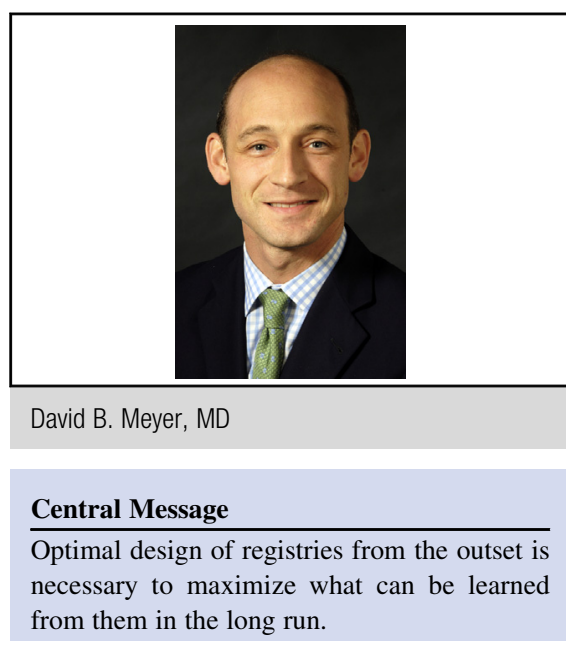

See Article page 1577.

These and other potential sources of bias are carefully acknowledged by the authors but are nonetheless important.

The assessment of functional health here is solely based on responses to a survey that is not disease specific, rather than also including objective data such as exercise tolerance or tailoring questions tailored to the subtleties of IAA. This may explain the unexpected finding that patients with IAA report themselves to be in some ways even more healthy than the general population. Again, the authors carefully acknowledge such potential bias, such as increased resilience or tolerance to pain, or reduced expectation of overall health, impacting patients' own assessment.

Although these data might represent the best that we have, going forward it would seem better if our data came from more inclusive databases and outcome analyses included more comprehensive measuring tools. It is incumbent on anyone who believes in transparency of outcomes to participate in these efforts, both physicians and patients.

\section{References}

1. Jegatheeswaran A, Jacobs ML, Caldarone CA, Kirshbom PM, Williams WG Blackstone EH, et al. Self-reported functional health status following interrupted aortic arch repair: a Congenital Heart Surgeons' Society study. J Thorac Cardiovasc Surg. 2019;157:1577-87.e10.

2. Schreiber C, Eicken A, Vogt M, Günther T, Wottke M, Thielmann M, et al. Repair of interrupted aortic arch: results after more than 20 years. Ann Thorac Surg. 2000; 70:1896-9

3. Sugimoto A, Ota N, Miyakoshi C, Murata M, Ide Y, Tachi M, et al. Mid- to long-term aortic valve related outcomes after conventional repair for patients with interrupted aortic arch or coarctation of the aorta, combined with ventricular septal defect: the impact of bicuspid aortic valve. Eur J Cardiothorac Surg. 2014; 46:952-60. 